\title{
Communication \\ Line-Field Confocal Optical Coherence Tomography May Enhance Monitoring of Superficial Basal Cell Carcinoma Treated with Imiquimod 5\% Cream: A Pilot Study
}

\author{
Anna Elisa Verzì, Giuseppe Micali and Francesco Lacarrubba *D \\ Dermatology Clinic, University of Catania, 95123 Catania, Italy; aeverzi@gmail.com (A.E.V.); \\ giuseppe.micali@unict.it (G.M.) \\ * Correspondence: francesco.lacarrubba@unict.it
}

Citation: Verzì, A.E.; Micali, G.; Lacarrubba, F. Line-Field Confocal Optical Coherence Tomography May Enhance Monitoring of Superficial Basal Cell Carcinoma Treated with Imiquimod 5\% Cream: A Pilot Study. Cancers 2021, 13, 4913. https:// doi.org/10.3390/cancers13194913

Academic Editor: Jose Manuel Lopes

Received: 26 July 2021

Accepted: 26 September 2021

Published: 30 September 2021

Publisher's Note: MDPI stays neutral with regard to jurisdictional claims in published maps and institutional affiliations.

Copyright: (C) 2021 by the authors Licensee MDPI, Basel, Switzerland. This article is an open access article distributed under the terms and conditions of the Creative Commons Attribution (CC BY) license (https:// creativecommons.org/licenses/by/ $4.0 /)$.
Simple Summary: Line-field confocal optical coherence tomography (LC-OCT) is a new non-invasive technique that allows the visualization of the epidermis and dermis and their different structures and findings at the cellular level, providing a sort of "virtual biopsy". The interest of using LC-OCT in the diagnosis of skin disorders is growing. The purpose of this study was to investigate if LC-OCT may be useful to enhance the monitoring of superficial basal cell carcinoma (BCC) in a series of patients treated with IQ 5\% cream, an immune response modifier currently approved in Europe and the USA. In our experience, LC-OCT was able to show sub-clinical signs of BCC after treatment, leading to a further cycle of IQ 5\% cream. Based on our preliminary results, LC-OCT may represent a promising tool able to enhance the evaluation of the treatment response of BCCs to non-surgical treatments.

Abstract: Line-field confocal optical coherence tomography (LC-OCT) is a novel, non-invasive technique for real-time skin imaging. Imiquimod (IQ) $5 \%$ cream is an immune response modifier currently approved for the treatment of small, superficial basal cell carcinoma (BCC). The aim of this study was to investigate if LC-OCT may be useful to enhance the treatment monitoring of BCC. Twenty superficial BCCs from 12 patients were treated with IQ 5\% cream once daily, five days a week, for six weeks. Clinical and LC-OCT evaluations were performed at baseline and 4 weeks after the end of treatment. At the end of the study, 13 lesions showed a complete clinical and LC-OCT response, 4 lesions a partial clinical and LC-OCT response, and 3 lesions a complete clinical response but residual tumoral signs at LC-OCT. Our pilot study suggests that LC-OCT may represent a promising tool able to enhance the evaluation of the treatment response of BCCs to non-invasive treatments. In our case series, its use highlighted, through a detailed, fast, and complete examination of the treated area, three cases of residual BCC that otherwise would have gone undetected at clinical examination. Future studies on larger series of patients treated with different modalities and with a longer follow-up are advisable.

Keywords: line-field confocal optical coherence tomography; LC-OCT; basal cell carcinoma; imiquimod; treatment monitoring

\section{Introduction}

Line-field confocal optical coherence tomography (LC-OCT) is a novel, non-invasive technique for real-time skin imaging [1,2]. It is based on a two-beam interference microscope with a combination of line illumination of the sample using a broadband light source (class one supercontinuum laser with a central wavelength of $800 \mathrm{~nm}$ ) and line detection (vertical section images from several A-scans acquired sequentially) using a line scan camera (that reads the image data one line at a time). It measures the echo time delay and amplitude of light backscattered from cutaneous microstructures through low-coherence interferometry associated with confocal spatial filtering [1,2]. 
LC-OCT allows the recognition and measurement of the different layers of the epidermis and dermis and their structures and findings at the cellular level, providing a sort of "virtual biopsy". It combines the advantages of both reflectance confocal microscopy (RCM) and optical coherence tomography (OCT) in terms of spatial resolution, penetration, and image orientation. In particular, it is able to provide high-resolution images (axial: $1.1 \mu \mathrm{m}$; lateral: $1.3 \mu \mathrm{m}$ ) in both vertical (or "en coupe", similarly to conventional OCT) and horizontal (or "en face", similarly to RCM) sections, with a penetration depth of up to $500 \mu \mathrm{m}$. Therefore, the resolution is higher than for conventional OCT (which is $\sim 10 \mu \mathrm{m}$ ) and the penetration depth is higher than for RCM (which is $\sim 200 \mu \mathrm{m}$ ) [3]. Moreover, LCOCT allows three-dimensional reconstructions and the acquisition of videos. The real-time acquisition of images is painless and causes no tissue damage; as a result, LC-OCT is totally safe to use on children and pregnant women.

The interest of using LC-OCT in the diagnosis of skin disorders is growing. Reported applications include benign dermal melanocytic proliferations [4], skin tumors such as actinic keratoses, squamous and basal cell carcinoma (BCC) [1,5-8], sebaceous hyperplasia [9], xanthogranuloma [10], autoimmune bullous diseases [11], herpes infection [12], scabies [13], aquagenic keratoderma [14], Kaposi's sarcoma [15], and circumscribed palmar hypokeratosis [16].

In particular, in BCC, the main LC-OCT features described include lobulated structures (tumor islands or nests) with variable shape, size, and location within the dermis. Blood vessels within the dermis are also visualized as hypo-reflective structures of various shape and size, with hyperreflective elements flowing within them $[1,6]$. Other structures frequently observed in BCC are represented by bright cells of various shape and size both within the epidermis and the lobules, histopathologically correlating to immunologically competent skin cells and activated melanocytes [6]. Lobules represent the main criterion as they correspond to the most distinctive histological feature of BCC: the aggregates of basaloid cells into the dermis. Lobules typically reveal an outer bright rim (possibly due to the compression exerted by the tumor islands on the collagen fibers) surrounding a middle dark rim (corresponding to peritumoral mucin deposition) and an inner grey core (corresponding to the dense cellularity) [6]. Because the orientation of the basaloid cells is prevalently parallel to the epidermis, these laminated structures resemble a specific pattern named as "millefeuille". LC-OCT allows the ability to assess the shape and location of the lobules, which are crucial to ascertain the BCC subtype. In superficial BCC, the lobules are connected to the epidermis. In nodular BCC, the stroma is modified, and the lobules are larger and not connected to the epidermis. In infiltrative BCC, the lobules are branched [6].

Imiquimod (IQ) is an immune response modifier currently approved in Europe and the USA as a $5 \%$ cream for the treatment of small, superficial BCCs in immunocompetent adults, applied five times per week for 6 weeks. In several studies it represented a valid alternative to surgery in the treatment of low-risk, single or multiple superficial BCC (grade of recommendation: A), with a complete response in about $80 \%$ of cases and good cosmetic outcomes [17-20].

The purpose of this study was to investigate if LC-OCT may be useful to enhance the monitoring of superficial BCC in a series of patients treated with IQ 5\% cream.

\section{Materials and Methods}

Twelve immunocompetent patients affected by single or multiple, primary, and small $(<2 \mathrm{~cm})$, superficial BCCs located outside of the high-risk T-zone of the face were enrolled in an open, pilot study. The diagnosis of BCC was based on clinical, dermoscopic, and LC-OCT examinations. Patients with Gorlin's syndrome and/or immunosuppressed were excluded. The study was approved by the local ethics committee and all subjects gave written informed consent prior to entry.

At baseline (T0), patients were instructed to apply, on one or more BCCs, a thin layer of IQ 5\% cream once daily, five consecutive days of the week, for six weeks, according to the leaflet schedule. The treatment area included a $1 \mathrm{~cm}$ margin of skin around the tumor. 
Clinical and LC-OCT evaluations were performed at baseline and 4 weeks after the end of treatment (T1, 10 weeks from baseline) in order to evaluate the response to treatment. During follow-up visits, missed applications were also checked.

LC-OCT was performed with the commercially available DeepLive ${ }^{\mathrm{TM}}$ (DAMAE Medical, Paris, France), which provides images with an axial resolution of $1.1 \mu \mathrm{m}$, a lateral resolution of $1.3 \mu \mathrm{m}$, and a field of view of $1.2 \mathrm{~mm} \times 0.5 \mathrm{~mm} \times 0.5 \mathrm{~mm}$. The device has a central unit connected to a handheld probe and a monitor where images are displayed in a grey scale based on the light backscattering from the sample microstructures. Immersion oil is applied between the glass window of the probe and the skin surface for index matching, thus reducing the specular back reflection [1]. As the operator gently moves the probe over the patient skin, live images are displayed on the monitor in real time. The compact handheld probe has a small imaging head, which is advantageous for examining difficult-to-access regions of the skin (including lips, ears, periocular area, conjunctiva, genitals, glans mucosa, interdigital spaces, etc.). The probe integrates a dermoscopic camera that allows the visualization of the exact area where the examination is performed, also reducing the risks connected to relocation or slipping of the probe.

Characteristic LC-OCT features indicative of superficial BCC included the presence of lobules (characterized by a millefeuille pattern, clefting, and a bright rim) connected to the epidermis.

\section{Results}

A total of 20 superficial BCCs from 12 Caucasian patients ( 5 males and 7 females, mean age 67.4 years, range 31-82) were evaluated (Table 1). Twelve BCC were located on the trunk, five on the face, one on the neck, one on the shoulder, and one on the forearm.

Table 1. Summary of results.

\begin{tabular}{|c|c|c|c|c|c|}
\hline \multirow[t]{2}{*}{$\begin{array}{l}\text { Patient's } \\
\text { Number }\end{array}$} & \multirow[t]{2}{*}{$\begin{array}{l}\text { Sex/Age } \\
\text { (Years) }\end{array}$} & \multirow[t]{2}{*}{ Localization } & \multirow[t]{2}{*}{$\begin{array}{l}\text { Lesion Size } \\
(\mathrm{mm})\end{array}$} & \multicolumn{2}{|c|}{$\begin{array}{c}\text { Response after } 10 \text { Weeks } \\
\text { (Four Weeks after the End } \\
\text { of Treatment) }\end{array}$} \\
\hline & & & & Clinical & LC-OCT \\
\hline \multirow{3}{*}{ Pt. 1} & \multirow{3}{*}{$\mathrm{F} / 43$} & Chest & $14 \times 9$ & Complete & Complete \\
\hline & & Back & $20 \times 16$ & Complete & Partial \\
\hline & & Shoulder & $10 \times 8$ & Complete & Complete \\
\hline \multirow{2}{*}{ Pt. 2} & \multirow{2}{*}{$\mathrm{F} / 72$} & Chest & $12 \times 12$ & Complete & Complete \\
\hline & & Chest & $18 \times 10$ & Complete & Complete \\
\hline Pt. 3 & $\mathrm{~F} / 66$ & Back & $18 \times 16$ & Complete & Complete \\
\hline \multirow{3}{*}{ Pt. 4} & \multirow{3}{*}{$\mathrm{M} / 73$} & Back & $20 \times 20$ & Complete & Partial \\
\hline & & Back & $16 \times 14$ & Complete & Complete \\
\hline & & Back & $18 \times 15$ & Complete & Complete \\
\hline Pt. 5 & $\mathrm{~F} / 79$ & Back & $16 \times 5$ & Complete & Partial \\
\hline Pt. 6 & $\mathrm{M} / 79$ & Neck & $12 \times 5$ & Complete & Complete \\
\hline \multirow{4}{*}{ Pt. 7} & \multirow{4}{*}{$\mathrm{M} / 82$} & Right cheek & $20 \times 18$ & Partial & Partial \\
\hline & & Right cheek & $18 \times 13$ & Complete & Complete \\
\hline & & Left cheek & $20 \times 20$ & Partial & Partial \\
\hline & & Left cheek & $18 \times 18$ & Complete & Complete \\
\hline Pt. 8 & $\mathrm{M} / 73$ & Back & $16 \times 14$ & Complete & Complete \\
\hline Pt. 9 & $\mathrm{M} / 69$ & Back & $20 \times 13$ & Complete & Complete \\
\hline
\end{tabular}


Table 1. Cont.

\begin{tabular}{cccccc}
\hline $\begin{array}{c}\text { Patient's } \\
\text { Number }\end{array}$ & $\begin{array}{c}\text { Sex/Age } \\
\text { (Years) }\end{array}$ & Localization & $\begin{array}{c}\text { Lesion Size } \\
\text { (mm) }\end{array}$ & \multicolumn{2}{c}{$\begin{array}{c}\text { Response after 10 Weeks } \\
\text { (Four Weeks after the End } \\
\text { of Treatment) }\end{array}$} \\
\hline Pt. 10 & F/65 & Chest & $20 \times 17$ & Partial & Partial \\
\hline Pt. 11 & F/77 & Forearm & $18 \times 17$ & Complete & Complete \\
\hline Pt. 12 & F/31 & Right cheek & $18 \times 16$ & Partial & Partial \\
\hline
\end{tabular}

At baseline (T0), all lesions showed, at LC-OCT, the presence of the characteristic features indicative of superficial BCC. All patients completed the 6 weeks of treatment, and no missed application was recorded. Nine patients reported the expected side effects of IQ such as erythema, edema, vesicles, erosions, ulcerations, excoriations, exudation, and crusting. After 10 weeks from baseline (T1), 13 lesions showed a complete clinical and LC-OCT response (Figure 1), 4 lesions showed a partial clinical and LC-OCT response and were addressed by surgical excision, and 3 lesions showed a complete clinical response but persistent signs of residual BCC at LC-OCT (lobules connected to the epidermis) (Figure 2), which were addressed by a further cycle of IQ 5\% cream.
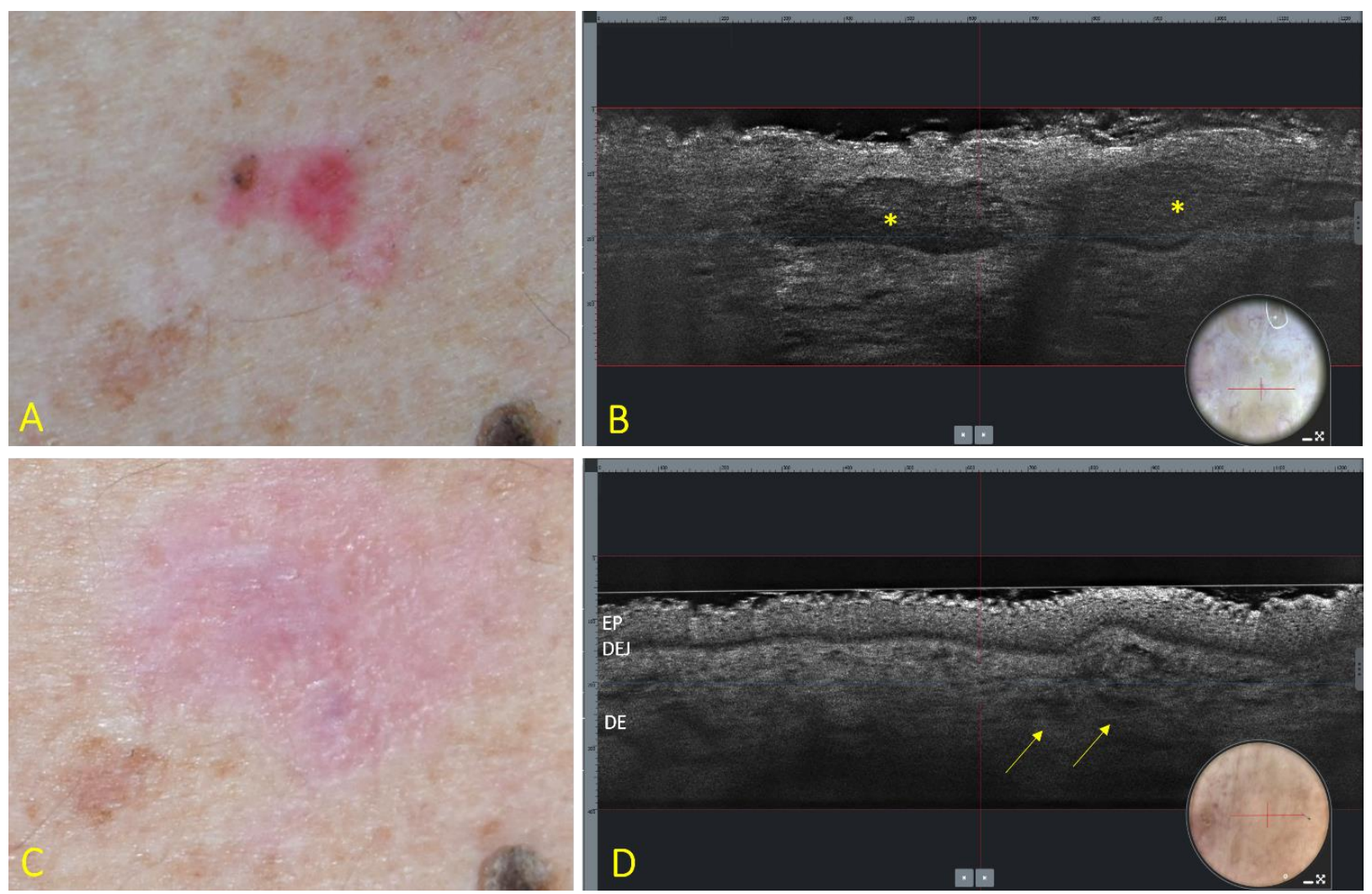

Figure 1. Superficial BCC of the trunk at baseline (A,B) and 4 weeks after the end of treatment with IQ $5 \%$ cream (C,D). (A) Clinical aspect showing a $16 \times 14 \mathrm{~mm}$, pink-reddish, and partially pigmented patch. (B) LC-OCT vertical section (field of view: $1200 \times 250 \mu \mathrm{m}$ ) showing the presence of lobules (asterisks) connected to the epidermis, with an outer bright rim surrounding a middle dark rim, and an inner grey core with a "millefeuille" pattern. Insert: dermoscopy of the examined area (field of view: $1200 \times 500 \mu \mathrm{m}$ ); the red line corresponds to the vertical section. (C) Clinical disappearance of the lesion with mild residual erythema. (D) LC-OCT showing disappearance of the lobules with persistence of dilated vessels (arrows). $\mathrm{EP}=$ epidermis; $\mathrm{DEJ}=$ dermoepidermal junction; $\mathrm{DE}=$ dermis. Insert: dermoscopy of the examined lesion (field of view: $1200 \times 500 \mu \mathrm{m})$; the red line corresponds to the vertical section. 

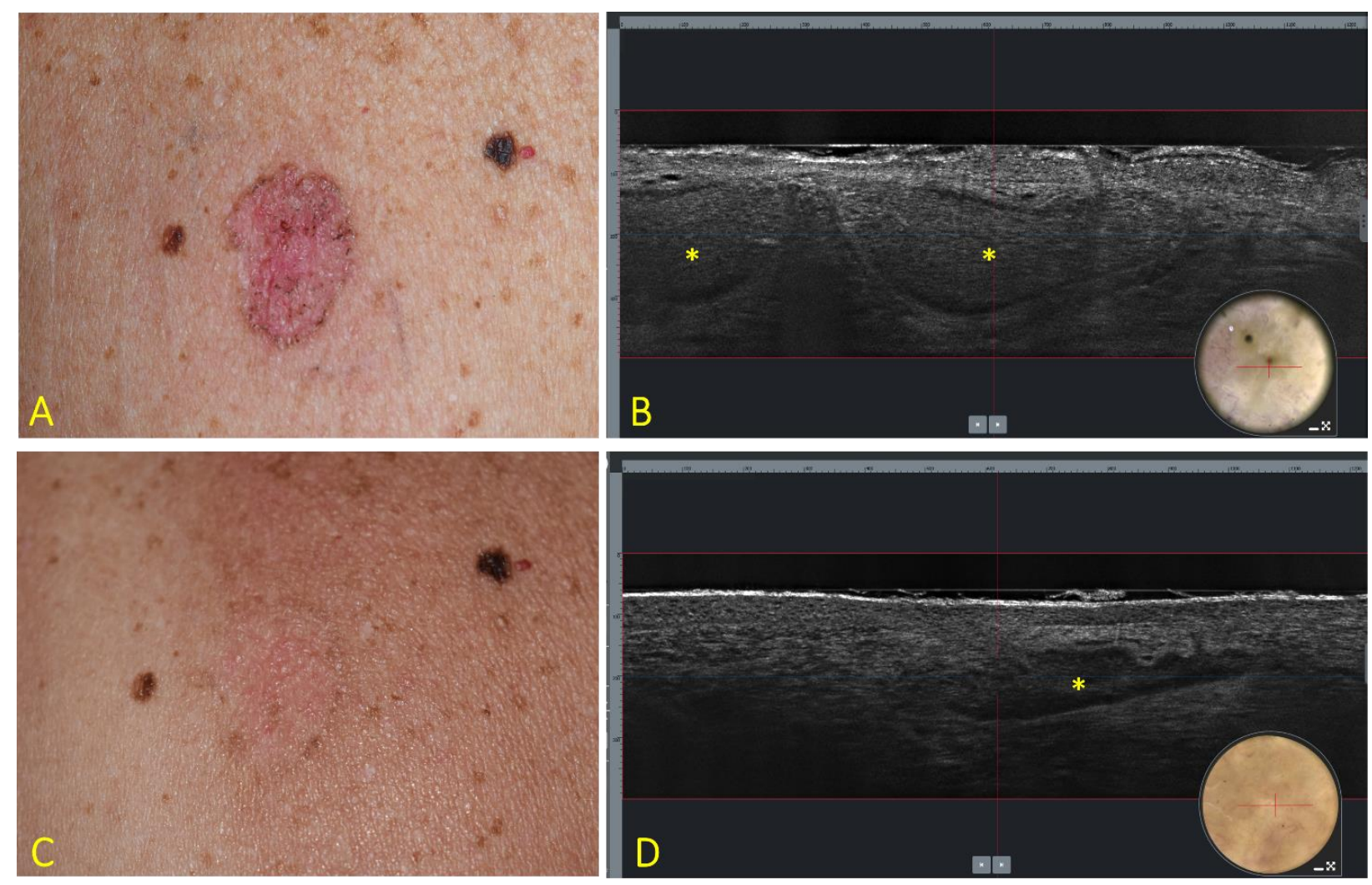

Figure 2. Superficial BCC of the trunk at baseline (A,B) and 4 weeks after the end of treatment with IQ 5\% cream (C,D). (A) Clinical aspect showing a $18 \times 12 \mathrm{~mm}$, roundish, and reddish patch with pigmented areas. (B) LC-OCT vertical section (field of view: $1200 \times 250 \mu \mathrm{m}$ ) showing the presence of lobules (asterisks) connected to the epidermis with an outer bright rim surrounding a middle dark rim, and an inner grey core with a "millefeuille" pattern. Insert: dermoscopy of the examined lesion (field of view: $1200 \times 500 \mu \mathrm{m}$ ); the red line corresponds to the vertical section. (C) Clinical disappearance of the lesion with mild residual erythema. (D) LC-OCT showing persistence of BCC lobules (asterisk). Insert: dermoscopy of the examined area (field of view: $1200 \times 500 \mu \mathrm{m}$ ); the red line corresponds to the vertical section.

\section{Discussion}

Basal cell carcinoma (BCC) is the most common non-melanoma skin cancer, with incidence rates rising each year [17]. Although rarely metastasizing, if not recognized and adequately treated it can lead to significant local destruction and morbidity. More than $95 \%$ of BCCs are easily treated with standard surgery or medical/physical alternative treatments [21]. Surgical therapy represents the "gold standard" because of high cure rates and histological confirmation of tumor clearance. However, in cases of low-risk BCC, such as small, superficial BCC and small, thin, and nodular BCC in immunocompetent subjects, some nonsurgical treatment options may be considered, including IQ $5 \%$ cream, 5 -fluorouracil 5\%, and photodynamic therapy [20,22].

The aim of this pilot study was to assess if LC-OCT may non-invasively enhance the treatment monitoring of BCC. In general, the response of BCC to non-surgical treatment is assessed by clinical inspection which, however, cannot exclude the persistence of subclinical disease responsible for relapses. On the other hand, post-treatment biopsies for histopathology confirmation of resolution are rarely performed, as they only analyze partial samples. Additionally, multiple biopsies impair the advantages of a lack of invasiveness and good aesthetic results due to the use of non-invasive treatments [23]. Based on this, the use of non-invasive techniques able to recognize sub-clinical signs of BCC persistence is advisable, and some experiences have been published utilizing dermoscopy, reflectance confocal microscopy, and optical coherence tomography [23-30].

Our pilot study suggests that LC-OCT may represent a promising tool that is able to enhance the evaluation of the treatment response of BCCs to non-invasive treatments, 
such as IQ 5\% cream. In our case series, its use highlighted, through a detailed, fast, and complete examination of the treated area, three cases of residual BCC that otherwise would have gone undetected at clinical examination. In particular, after completing the 6-week treatment cycle with IQ 5\% cream, clinical examination showed, in agreement with the existing literature, a complete response in $80 \%$ of cases (16 out of 20 BCC) and a partial response in the remaining 20\% (four cases). However, LC-OCT analysis revealed residual BCC lobules in 7 out of 20 lesions, with three of these lesions appearing to have cleared at clinical evaluation. All lesions presenting clinical and/or LC-OCT persistence of BCC were addressed by surgical excision or by a further cycle of IQ 5\% cream. Of note, the integrated dermoscopic camera allowed a precise, timely positioning over the same areas of interest before and after treatment.

In conclusion, our data show that LC-OCT may reveal microscopic signs of residual disease in some superficial BCCs treated with IQ 5\% cream that appear clinically healed, thus suggesting further treatment. Limitations of our study include the small sample size, the lack of biopsy before and after treatment, and the short follow-up period. Another limit is the lack of resolution of LC-OCT at deeper layers, so the deep presence of BCC nests in the dermis after treatment cannot be excluded, although in the case of superficial BCC this occurrence seems quite rare $[23,29]$. Future studies on larger series of patients treated with different modalities and with a longer follow-up are advisable.

Author Contributions: Conceptualization, A.E.V., G.M. and F.L.; Methodology, A.E.V., G.M. and F.L.; Investigation, A.E.V., G.M. and F.L.; Data Curation, A.E.V., G.M. and F.L.; Writing-Original Draft Preparation, A.E.V., G.M. and F.L.; Writing-Review and Editing, A.E.V., G.M. and F.L. All authors have read and agreed to the published version of the manuscript.

Funding: This research received no external funding.

Institutional Review Board Statement: The study was conducted according to the guidelines of the Declaration of Helsinki, and approved by the Institutional Review Board (Catania1 \#3657/21).

Informed Consent Statement: Informed consent was obtained from all subjects involved in the study.

Data Availability Statement: The data presented in this study are available on request from the corresponding author.

Conflicts of Interest: The authors declare no conflict of interest.

\section{References}

1. Dubois, A.; Levecq, O.; Azimani, H.; Siret, D.; Barut, A.; Suppa, M.; Del Marmol, V.; Malvehy, J.; Cinotti, E.; Rubegni, P.; et al. Line-field confocal optical coherence tomography for high-resolution noninvasive imaging of skin tumors. J. Biomed. Opt. 2018, 23, 106007. [CrossRef] [PubMed]

2. Krišto, M.; Šitum, M.; Čeović, R. Noninvasive Imaging Techniques for the Diagnosis of Nonmelanoma Skin Cancers. Acta Dermatovenerol. Croat. 2020, 28, 157-165. [PubMed]

3. Ruini, C.; Schuh, S.; Sattler, E.; Welzel, J. Line-field confocal optical coherence tomography-Practical applications in dermatology and comparison with established imaging methods. Skin Res. Technol. 2021, 27, 340-352. [CrossRef] [PubMed]

4. Lenoir, C.; Perez-Anker, J.; Diet, G.; Tognetti, L.; Cinotti, E.; Trépant, A.L.; Rubegni, P.; Puig, S.; Perrot, J.L.; Malvehy, J.; et al. Line-field confocal optical coherence tomography of benign dermal melanocytic proliferations: A case series. J. Eur. Acad. Dermatol. Venereol. 2021, 35, e399-e401. [PubMed]

5. Dejonckheere, G.; Suppa, M.; Del Marmol, V.; Meyer, T.; Stockfleth, E. The actinic dysplasia syndrome-Diagnostic approaches defining a new concept in field carcinogenesis with multiple cSCC. J. Eur. Acad. Dermatol. Venereol. 2019, 33 (Suppl. 8), 16-20. [CrossRef]

6. Suppa, M.; Fontaine, M.; Dejonckheere, G.; Cinotti, E.; Yélamos, O.; Diet, G.; Tognetti, L.; Miyamoto, M.; Orte Cano, C.; PerezAnker, J.; et al. Line-field confocal optical coherence tomography of basal cell carcinoma: A descriptive study. J. Eur. Acad. Dermatol. Venereol. 2021, 35, 1099-1110. [CrossRef]

7. Ruini, C.; Schuh, S.; Gust, C.; Kendziora, B.; Frommherz, L.; French, L.E.; Hartmann, D.; Welzel, J.; Sattler, E. Line-field optical coherence tomography: In vivo diagnosis of basal cell carcinoma subtypes compared to histopathology. Clin. Exp. Dermatol. 2021. epub ahead of print. [CrossRef]

8. Cinotti, E.; Tognetti, L.; Cartocci, A.; Lamberti, A.; Gherbassi, S.; Orte Cano, C.; Lenoir, C.; Dejonckheere, G.; Diet, G.; Fontaine, M.; et al. Line-field confocal optical coherence tomography for actinic keratosis and squamous cell carcinoma: A descriptive study. Clin. Exp. Dermatol. 2021. epub ahead of print. [CrossRef] 
9. Lenoir, C.; Diet, G.; Cinotti, E.; Tognetti, L.; Orte Cano, C.; Rocq, L.; Trépant, A.L.; Monnier, J.; Perez-Anker, J.; Rubegni, P.; et al. Line-field confocal optical coherence tomography of sebaceous hyperplasia: A case series. J. Eur. Acad. Dermatol. Venereol. 2021, 35, e509-e511.

10. Lacarrubba, F.; Verzì, A.E.; Puglisi, D.F.; Broggi, G.; Caltabiano, R.; Micali, G. Line-field confocal optical coherence tomography of xanthogranuloma: Correlation with vertical and horizontal histopathology. J. Cutan. Pathol. 2021, 48, 1208-1211. [CrossRef]

11. Tognetti, L.; Cinotti, E.; Suppa, M.; Guazzo, R.; Habougit, C.; Santi, F.; Diet, G.; Fontaine, M.; Berot, V.; Monnier, J.; et al. Line field confocal optical coherence tomography: An adjunctive tool in the diagnosis of autoimmune bullous diseases. J. Biophotonics 2021, 14, e202000449. [CrossRef]

12. Lacarrubba, F.; Verzì, A.E.; Puglisi, D.F.; Micali, G. Line-field confocal optical coherence tomography: A novel, non-invasive imaging technique for a rapid, in-vivo diagnosis of herpes infection of the skin. J. Eur. Acad. Dermatol. Venereol. 2021, 35, e404-e406. [CrossRef]

13. Ruini, C.; Schuh, S.; Pellacani, G.; French, L.; Welzel, J.; Sattler, E. In vivo imaging of Sarcoptes scabiei infestation using line-field confocal optical coherence tomography. J. Eur. Acad. Dermatol. Venereol. 2020, 34, e808-e809. [CrossRef]

14. Tognetti, L.; Fiorani, D.; Cinotti, E.; Rubegni, P. Tridimensional skin imaging in aquagenic keratoderma: Virtual histology by line-field confocal optical coherence tomography. Int. J. Dermatol. 2021, 60, e52-e54. [CrossRef] [PubMed]

15. Tognetti, L.; Carraro, A.; Lamberti, A.; Cinotti, E.; Suppa, M.; Luc Perrot, J.; Rubegni, P. Kaposi sarcoma of the glans: New findings by line field confocal optical coherence tomography examination. Skin Res. Technol. 2021, 27, 285-287. [CrossRef]

16. Tognetti, L.; Fiorani, D.; Suppa, M.; Cinotti, E.; Fontaine, M.; Marmol, V.D.; Rubegni, P.; Perrot, J.L. Examination of circumscribed palmar hypokeratosis with line-field confocal optical coherence tomography: Dermoscopic, ultrasonographic and histopathologic correlates. Indian J. Dermatol. Venereol. Leprol. 2020, 86, 206-208. [CrossRef] [PubMed]

17. Peris, K.; Fargnoli, M.C.; Garbe, C.; Kaufmann, R.; Bastholt, L.; Seguin, N.B.; Bataille, V.; Marmol, V.D.; Dummer, R.; Harwood, C.A.; et al. Diagnosis and treatment of basal cell carcinoma: European consensus-based interdisciplinary guidelines. Eur. J. Cancer 2019, 118, 10-34. [CrossRef] [PubMed]

18. Micali, G.; Lacarrubba, F.; Dinotta, F.; Massimino, D.; Nasca, M.R. Treating skin cancer with topical cream. Expert Opin. Pharmacother. 2010, 11, 1515-1527. [CrossRef] [PubMed]

19. Micali, G.; Lacarrubba, F.; Nasca, M.R.; Ferraro, S.; Schwartz, R.A. Topical pharmacotherapy for skin cancer: Part II. Clinical applications. J. Am. Acad. Dermatol. 2014, 70, 979.e1-979.e12. [CrossRef]

20. Cameron, M.C.; Lee, E.; Hibler, B.P.; Giordano, C.N.; Barker, C.A.; Mori, S.; Cordova, M.; Nehal, K.S.; Rossi, A.M. Basal cell carcinoma: Contemporary approaches to diagnosis, treatment, and prevention. J. Am. Acad. Dermatol. 2019, 80, 321-339. [CrossRef]

21. Lang, B.M.; Balermpas, P.; Bauer, A.; Blum, A.; Brölsch, G.F.; Dirschka, T.; Follmann, M.; Frank, J.; Frerich, B.; Fritz, K.; et al. S2k Guidelines for Cutaneous Basal Cell Carcinoma-Part 1: Epidemiology, Genetics and Diagnosis. J. Dtsch. Dermatol. Ges. 2019, 17, 94-103. [CrossRef] [PubMed]

22. Nasr, I.; McGrath, E.J.; Harwood, C.A.; Botting, J.; Buckley, P.; Budny, P.G.; Fairbrother, P.; Fife, K.; Gupta, G.; Hashme, M.; et al. British Association of Dermatologists guidelines for the management of adults with basal cell carcinoma 2021. Br. J. Dermatol. 2021. epub ahead of print. [CrossRef] [PubMed]

23. Venturini, M.; Sala, R.; Gonzàlez, S.; Calzavara-Pinton, P.G. Reflectance confocal microscopy allows in vivo real-time noninvasive assessment of the outcome of methyl aminolaevulinate photodynamic therapy of basal cell carcinoma. Br. J. Dermatol. 2013, 168, 99-105. [CrossRef]

24. Goldgeier, M.; Fox, C.A.; Zavislan, J.M.; Harris, D.; Gonzalez, S. Noninvasive imaging, treatment, and microscopic confirmation of clearance of basal cell carcinoma. Dermatol. Surg. 2003, 29, 205-210. [PubMed]

25. Micantonio, T.; Fargnoli, M.C.; Piccolo, D.; Peris, K. Letter: Changes in dermoscopic features in superficial basal cell carcinomas treated with imiquimod. Dermatol. Surg. 2007, 33, 1403-1405. [CrossRef] [PubMed]

26. Apalla, Z.; Lallas, A.; Tzellos, T.; Sidiropoulos, T.; Lefaki, I.; Trakatelli, M.; Sotiriou, E.; Lazaridou, E.; Evangelou, G.; Patsatsi, A.; et al. Applicability of dermoscopy for evaluation of patients' response to nonablative therapies for the treatment of superficial basal cell carcinoma. Br. J. Dermatol. 2014, 170, 809-815. [CrossRef]

27. Husein-ElAhmed, H.; Fernandez-Pugnaire, M.A. Dermatoscopy-guided therapy of pigmented basal cell carcinoma with imiquimod. An. Bras. Dermatol. 2016, 91, 764-769. [CrossRef]

28. Torres, A.; Niemeyer, A.; Berkes, B.; Marra, D.; Schanbacher, C.; González, S.; Owens, M.; Morgan, B. 5\% imiquimod cream and reflectance-mode confocal microscopy as adjunct modalities to Mohs micrographic surgery for treatment of basal cell carcinoma. Dermatol. Surg. 2004, 30 Pt 1, 1462-1469.

29. Manubens, E.; Barreiro, A.; Bennassar, A.; Podlipnik, S.; Moreno, N.; Iglesias, P.; Malvehy, J.; Puig, S. Fast evaluation and monitoring of ingenol mebutate treatment of multiple basal cell carcinomas by in vivo hand-held reflectance confocal microscopy. J. Eur. Acad. Dermatol. Venereol. 2017, 31, e284-e286. [CrossRef]

30. Banzhaf, C.A.; Phothong, W.; Suku, M.H.; Ulrich, M.; Philipsen, P.A.; Mogensen, M.; Haedersdal, M. Basal cell carcinoma treated with combined ablative fractional laser and ingenol mebutate-An exploratory study monitored by optical coherence tomography and reflectance confocal microscopy. J. Eur. Acad. Dermatol. Venereol. 2020, 34, 502-509. [CrossRef] 